\title{
An Engineered Tryptophan Synthase Opens New Enzymatic Pathways to -Methyltryptophan and Derivatives.
}

DOI:

10.1002/cbic. 201600471

\section{Document Version}

Accepted author manuscript

Link to publication record in Manchester Research Explorer

\section{Citation for published version (APA):}

Francis, D., Winn, M., Latham, J., Greaney, M., \& Micklefield, J. (2017). An Engineered Tryptophan Synthase Opens New Enzymatic Pathways to -Methyltryptophan and Derivatives. ChemBioChem: a European journal of chemical biology , 18(4), 382-386. https://doi.org/10.1002/cbic.201600471

\section{Published in:}

ChemBioChem: a European journal of chemical biology

\section{Citing this paper}

Please note that where the full-text provided on Manchester Research Explorer is the Author Accepted Manuscript or Proof version this may differ from the final Published version. If citing, it is advised that you check and use the publisher's definitive version.

\section{General rights}

Copyright and moral rights for the publications made accessible in the Research Explorer are retained by the authors and/or other copyright owners and it is a condition of accessing publications that users recognise and abide by the legal requirements associated with these rights.

\section{Takedown policy}

If you believe that this document breaches copyright please refer to the University of Manchester's Takedown Procedures [http://man.ac.uk/04Y6Bo] or contact uml.scholarlycommunications@manchester.ac.uk providing relevant details, so we can investigate your claim.

\section{OPEN ACCESS}




\title{
An Engineered Tryptophan Synthase Opens New Enzymatic Pathways to $\beta$-Methyltryptophan and Derivatives.
}

\author{
Daniel Francis, Michael Winn, Jonathan Latham, Michael F. Greaney and Jason Micklefield*
}

\begin{abstract}
Methyltryptophans ( $\beta$-mTrp) are precursors in the biosynthesis of bioactive natural products and are used in the synthesis of peptidomimetic based therapeutics. Currently $\beta$-mTrp is produced by inefficient multi-step synthetic methods. Here we demonstrate how an engineered variant of tryptophan synthase from Salmonella (StTrpS) can catalyse the efficient condensation of $L$ threonine and various indoles to generate $\beta-m$ Trp and derivatives in a single step. Although L-serine is the natural substrate for TrpS, targeted mutagenesis of the StTrpS active site provided a variant (BL166V) which can better accommodate L-Thr as a substrate. The condensation of $L-T h r$ and indole proceeds with retention of configuration at both $\alpha$ - and $\beta$-positions leading to (2S,3S)- $\beta-m$ Trp. The integration of StTrpS ( $\beta L 166 \mathrm{~V})$ with L-amino acid oxidase, halogenase enzymes and palladium chemocatalysts provides access to further $D$-configured and regioselectively halogenated or arylated $\beta$-mTrp derivatives.
\end{abstract}

$\beta$-Methyl-a-amino acids are important building blocks in the synthesis of peptidomimetics and other pharmaceuticals (for examples see Scheme $1 A$ \& S1). ${ }^{[1]}$ The introduction of a $\beta$ methyl substituent into synthetically modified peptides reduces the conformational freedom of the amino acid side chain, reducing the entropic penalty of binding to a biological receptor, resulting in higher affinity and improved biological activity. ${ }^{[2]}$ In light of this, $\beta$-branched synthetic peptides have been used to develop improved $\delta$ opioid agonists, somatostatin receptor agonists, cholecystokinin B receptor agonists, glucagon receptor antagonists and AT4 receptor antagonists. ${ }^{[1,3]}$ Nature has also adopted the strategy of introducing $\beta$-methyl- $\alpha$-amino acids into peptides, alkaloids and other bioactive natural products (for examples see Scheme $1 \mathrm{~A} \& \mathrm{~S} 2),{ }^{[4]}$ which presumably also serves to pre-organise the amino acid side chain for tighter binding to molecular targets in vivo.

The prominence of $\beta$-methyl- $\alpha$-amino acids in synthetic peptides, natural products and other valuable compounds has resulted in the development of many methods for the synthesis of $\beta$-methyl amino acids including: $\beta$-lactone ring opening; alkylation of imines using secondary sulfonates; $[3,3]$ sigmatropic rearrangements; the use of chiral auxiliaries and/or kinetic resolutions. ${ }^{[5]}$ Many of these and other approaches require laborious multi-step synthetic procedures, use deleterious reagents and often fail to provide enantiomerically pure products In contrast, there have been relatively few enzymatic approaches used in the preparation of $\beta$-methyl- $\alpha$-amino acids, despite the inherent advantages of enzymes which include high stereoselectivity and cleaner, more benign aqueous reaction conditions. Previously, we elucidated the biosynthesis of $\beta$ methylglutamic acid, which involved the $S$-adenosylmethionine

\footnotetext{
D. Francis, Dr. M. Winn, J. Latham, Prof. M. F. Greaney \&

Prof. J. Micklefield ${ }^{\star}$

School of Chemistry \& Manchester Institute of Biotechnology,

The University of Manchester,

131 Princess Street, Manchester M1 7DN

E-mail: jason.micklefield@manchester.ac.uk
}

Supporting information for this article is given via a link at the end of the document.((Please delete this text if not appropriate))

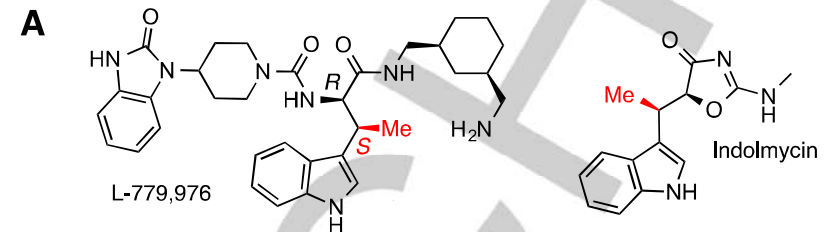

B
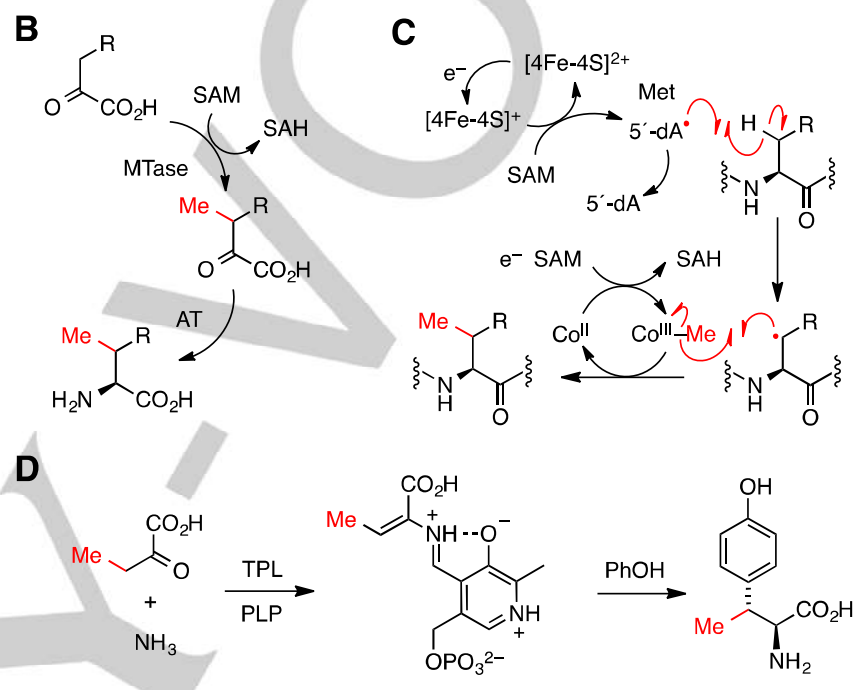

Scheme 1. (A) Synthetic peptidomimetic L-779,976 a somatostatin agonist and diabetes drug candidate from Merck, ${ }^{[1 \mathrm{c}, \mathrm{d}]}$ and the antibiotic indolmycin from Streptomyces griseus. ${ }^{[4 \mathrm{~h}]}$ (B) $\alpha$-Ketoacid MTase and aminotransferase (AT) enzymes produce $\beta$-Methyl- $\alpha$-amino acids ${ }^{[6,7]}$ including $\beta$-mTrp. ${ }^{[7 a]}$ (C) Radical SAM MTases are predicted to catalyze $\beta$-methylation of amino acid residues in peptide natural products with a $5^{\prime}$-deoxyadenosine $\left(5^{\prime}\right.$-dA $)$ radical likely to abstract the $\beta$-hydrogen atoms facillitating subsequent $\beta$-methylation with methylcobalamin (Co ${ }^{\text {III- }-M e) .}{ }^{[8]}$ (D) TPL catalysed preparation of $(2 S, 3 R)$ $\beta$-methyltyrosine..$^{[9]}$

(SAM)-dependent methyltransferase (MTase) catalyzed methylation of $\alpha$-ketoglutarate and subsequent transamination by an aminotransferase (AT) enzyme. ${ }^{[6]}$ Following this, a number of other $\alpha$-ketoacid MTase were identified and it transpired that this is a common strategy used in nature for the biosynthesis of $\beta$ methyl- $\alpha$-amino acids (Scheme $1 \mathrm{~B}$ ). ${ }^{[7]}$ More recently radical SAM-dependent MTase enzymes have been characterized ${ }^{[8]}$ and several members of this family have been predicted to $\beta$ methylate amino acid residues within peptides including bottromycin and polytheonamide precursors (Scheme 1C \& S2) ${ }_{[4 i, 4]}^{[4}$ Despite these insights, neither a-ketoacid MTases or the radical SAM-dependent MTases offer a viable means for the biocatalytic preparation of $\beta$-methylated amino acids or peptides. Firstly, SAM is an expensive co-factor and there are no effective ways available for recycling SAM in vitro. Also, to date, only a few radical SAM MTases have been characterized and these enzymes also require a cobalamin co-factor as well as a [4Fe4S] cluster that necessitates in vitro reconstitution under anaerobic conditions. ${ }^{\left[{ }^{[]}\right.}$An alternative approach to produce $\beta$ methyl- $\alpha$-amino acids is to exploit the promiscuity of enzymes from proteinogenic amino acid metabolism. For example tyrosine phenol-lyase (TPL), has been used to catalyse the reverse synthesis of $\beta$-methyltyrosine from $\alpha$-ketobutyrate, ammonia and phenol (Scheme 1D). ${ }^{[9]}$ 


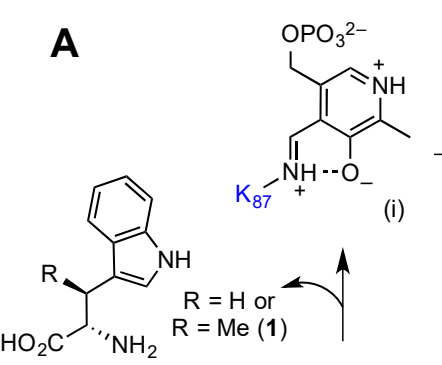

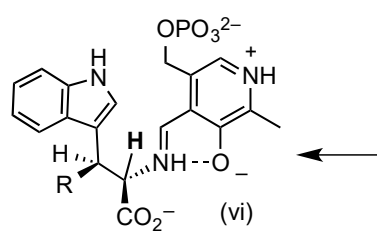
(vi)

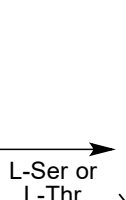

$\overbrace{87}^{\mathrm{K} H}$

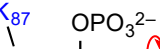

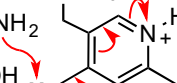
$\mathrm{OH}^{-1}$<smiles>CCCC(C)C</smiles>
$\mathrm{L}_{166}$ $\mathrm{CO}_{2}-$ (ii)<smiles>CCC(C)C</smiles>

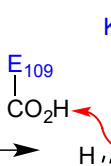

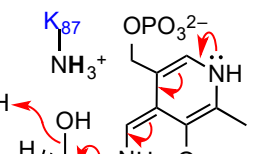

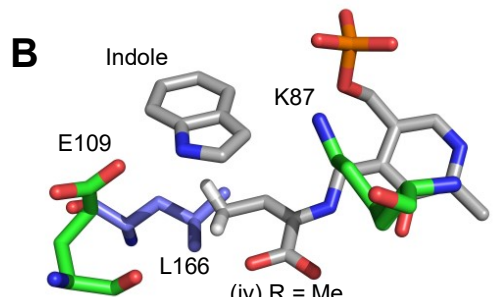

(iv) $\mathrm{R}=\mathrm{Me}$

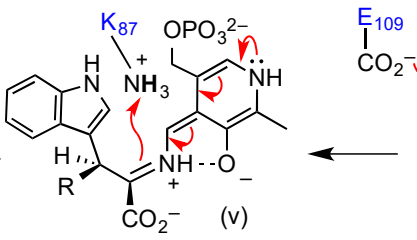

C

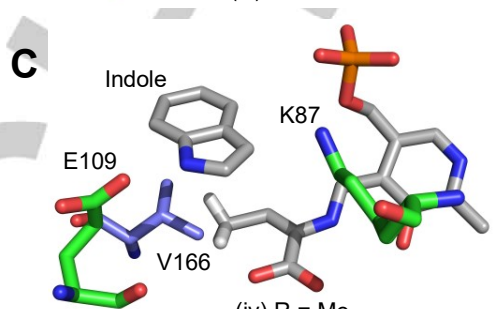

(iv) $\mathrm{R}=\mathrm{Me}$

Figure 1. (A) TrpS $\beta$ subunit reaction mechanism and stereochemical course. L-Ser reacts with the internal aldimine (i) to generate an external aldimine (ii) which is deprotonated by $\beta$ lys 87 to give quinone (iii) that facilitates elimination of the $\beta$-OH leading to the $\alpha$-aminoacrylate species (iv). It is then suggested that $\beta$ Glu109 deprotonates indole facilitating conjugate addition with (iv) leading to quinone (v) and L-Trp external aldimine (vi). (B) X-ray crystal structure (PDB4HPX) of the StTrpS $\beta$ subunit ${ }^{[13]}$ with an $(E)$-2-amino-2-butenoate intermediate (iv, $R=M e$ ). (C) Model of intermediate iv $(R=M e)$ bound to the $\beta L 166 \mathrm{~V}$ TrpS mutant.

In this paper we demonstrate how an engineered variant of tryptophan synthase (TrpS) can efficiently produce a range of enantiomerically pure $(2 S, 3 S)$ L- $\beta$-methyltryptophan ( $\beta$-mTrp) derivatives. Enzyme cascades utilizing the TrpS variant with Lamino acid oxidase (L-AAO) and halogenase enzymes provide access to more diverse L- and D- $\beta$-mTrp analogues. TrpS is a pyridoxal phosphate (PLP)-dependent enzyme comprising two subunits in a $\alpha_{2} \beta_{2}$ tetramer. The $\alpha$ subunit catalyses a retro aldol cleavage of indole 3-glycerol phosphate to liberate indole, which is then channelled to the $\beta$ subunit where an aldimine is formed between PLP and L-Ser facilitating dehydration and subsequent condensation with indole to give L-tryptophan (Figure $1 \mathrm{~A}) \cdot{ }^{[10]}$ As PLP is regenerated during the catalytic cycle, addition of an expensive stoichiometric co-factor is not required unlike the SAM-dependent methyltransferases. Moreover, PLP-dependent enzymes have already been demonstrated to have great potential for pharmaceutical synthesis. ${ }^{[11]}$ Previous studies have shown that TrpS from Salmonella typhimurium (StTrpS ATCC 37845 ) is promiscuous and will accept a number of indole derivatives. ${ }^{[12]}$ We wished to explore the possibility of utilising threonine as a substrate for StTrpS instead of serine, to generate $\beta$-mTrp 1 (Figures $1 \mathrm{~A} \& 3$ ). Accordingly StTrpS was overproduced in $E$. coli BL21(DE3) and the resulting cell free extract was incubated with indole and a ten-fold excess of L-Thr. The progress of the reaction was followed by HPLC (Figure S3) revealing the formation of a new product peak, $\beta-\mathrm{mTrp} 1$, which was observed to reach a maximum conversion of $60 \%( \pm 4 \%)$ after 5 hours (Figure S4). No production of $\beta$-mTrp 1 was evident in control assays when indole and L-Thr were incubated with standard BL21 lysate lacking StTrpS (Figure S3). Subsequent scale up, followed by solvent and solid-phase (C18) extractions led to the isolation of $\beta$-mTrp in a $54 \%$ yield, demonstrating for the first time that the wild type StTrpS can be harnessed to generate a $\beta$-methyl amino acid

While L-Thr is accepted as a substrate by StTrpS, the activity and isolated yields of L- $\beta-m T r p$ are low compared to the wild type reaction with L-Ser, which gives over $90 \%$ of L-Trp under the same conditions. The published crystal structure(s) of StTrpS show that a leucine residue ( $\beta$ L166) is in close proximity to the $\beta$-position of the $\alpha$-aminoacrylate species. ${ }^{[13]}$ With L-Thr as a substrate, the introduction of a methyl group in the corresponding (E)-2-amino-2-butenoate intermediate could lead to a steric hindrance with the side chain of $\beta$ L166 (Figure 1B) With this in mind, a StTrpS mutant was generated which replaced $\beta L 166$ with the less bulky valine. Cell lysate experiments carried out with this new mutant ( $\beta L 166 \mathrm{~V})$ showed improved activity compared to the wild-type with the conversion of indole to $\beta$-mTrp reaching $98 \%( \pm 0.2 \%)$ within 3 hours (Figure S4). SDS-Page analysis suggests that both wild-type and $\beta L 166 \mathrm{~V}$ lysates contain a similar amount of StTrpS protein (Figure S5). However, to facilitate direct comparison of the wildtype StTrpS and the $\beta L 166 \mathrm{~V}$ mutant, the $\beta$ subunits were expressed as hexahistidine fusion proteins and purified by metal affinity chromatography. The $\beta$-subunit was expressed individually to prevent the formation of heterologous mixtures of $\alpha_{2} \beta_{2}$ and $\beta_{2}$ complexes. Since the $\alpha_{2} \beta_{2}$ is more active than the $\beta_{2}{ }^{[14]}$ such unquantified mixtures could bias comparative activity assays between the wild-type and the mutant. The subsequent kinetic analysis revealed that the activity of the $\beta L 166 \mathrm{~V}$ mutant was ten-fold higher than the wildtype (Table 1). Presumably the increase in the size of the active site in the $\beta L 166 \mathrm{~V}$ mutant allows it to better accommodate L-Thr as a substrate (Figure 1C). An additional mutant was generated to further expand the space within the active site, $\beta$ L166A, but although this showed a fivefold improvement over the wild-type it was only half as active as $\beta L 166 V$. Replacing $\beta L 166$ with alanine may provide too much space within the active site, possibly allowing either the indole or the $(E)$-2-amino-2-butenoate intermediate to adopt a suboptimal conformation within the active site, leading to less efficient conjugate addition. It is worth noting that although the measured $k_{\text {cat }}$ of $\beta L 166 \mathrm{~V}$ with L-Thr is low, the enzyme functions in a slow but steady fashion, remaining stable and active within a crude cell lysate for several days, meaning good quantities of product can still be isolated. Also the rate of the $\alpha_{2} \beta_{2}$ tetramer present in the cell lysate will be higher than that of the purified $\beta_{2}$ complex observed here. Analysis of the kinetics with the natural substrate L-serine shows that activity towards serine is reduced in both of the two mutants. These results indicate that the $\beta \mathrm{L} 166 \mathrm{~V}$ mutant is a promising biocatalyst for the formation of enantiomerically pure $\beta$-mTrp derivatives. 


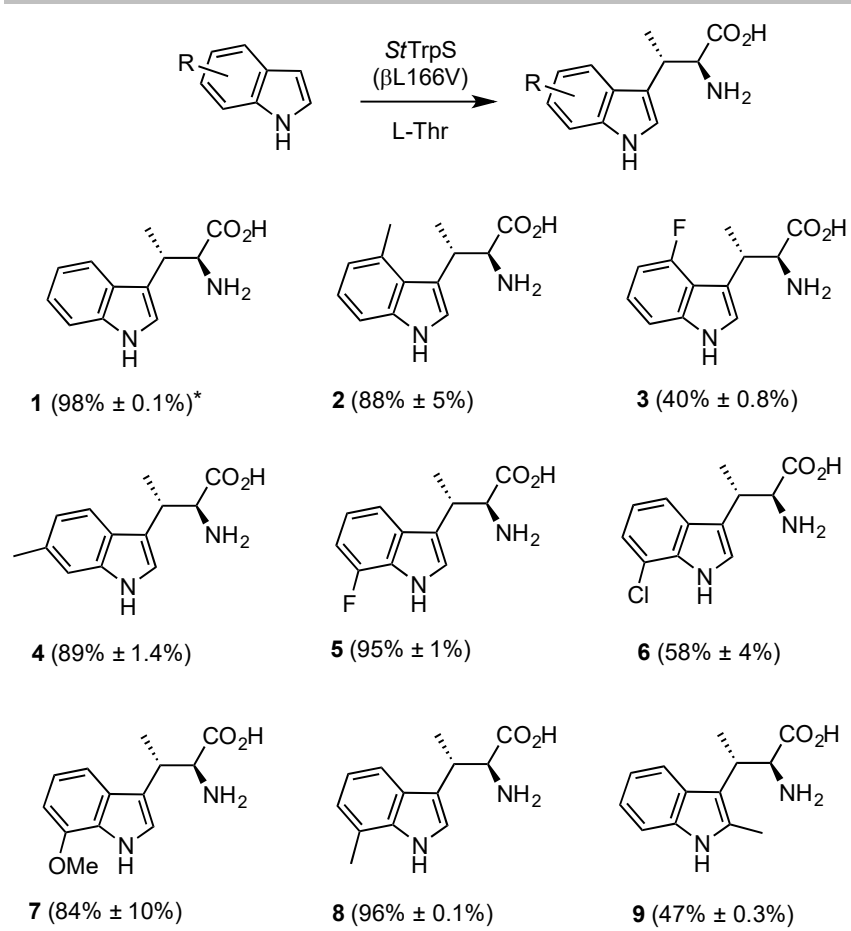

Scheme 2. The single step enzymatic synthesis of $\beta$-mTrp derivatives using the mutant StTrpS $\beta$ L166V (\% conversions after $4 \mathrm{~h}$, or * $3 \mathrm{~h}$ incubation).

Previous stereochemical studies with TrpS using labelled $(2 S, 3 R)$ - and $(2 S, 3 S)-\left[3-{ }^{3} \mathrm{H}\right]$-serine show that the dehydration and addition of indole to form L-Trp proceed with retention of configuration at C3 as well as at C2 (Figure 1A). ${ }^{[15]}$ Based on this information, combined with analysis of $\mathrm{X}$-ray crystal structures of StTrpS ${ }^{[13]}$ (Figure 1B), we predicted that the condensation of L-Thr and indole catalysed by StTrpS would proceed with indole addition to the $R e$ face of the $\beta$-carbon in an (E)-2-amino-2-butenoate intermediate (iv, $\mathrm{R}=\mathrm{CH}_{3}$ ) resulting in $(2 S, 3 S)-\beta-m T r p 1$. As anticipated the configuration of the $\beta-m T r p$ generated by both the wild-type StTrpS and the $\beta L 166 \mathrm{~V}$ mutant was confirmed to be $(2 S, 3 S)$ by comparison of optical rotation and NMR data (Figure S6), including a ${ }^{3} J_{\mathrm{HaH} \beta}$ coupling constant of $7.4 \mathrm{~Hz}$, with data from literature. ${ }^{[7 a]}$ The enantiomeric purity of the $\beta$-mTrp 1 was further assessed using L-amino acid oxidase (LAAO). Incubation of $\beta$-mTrp 1 with LAAO resulted in $>98 \%$ conversion of 1 to the corresponding $\alpha$-keto acid as determined by HPLC (Figure S7). Conversely when the $\beta$-mTrp 1 was incubated with D-amino acid oxidase (DAAO) under identical reaction conditions no $\alpha$-keto acid was formed (Figure S7).

To further explore the scope of the $\beta L 166 \mathrm{~V}$ mutant, biotransformations were carried out with a range of halogenated, methylated and methoxylated indoles (Scheme 2). This showed that the mutant could be used to generate $\beta$-mTrp derivatives (19) with substituents in either the 2-, 4-, 6- or 7-positions of the indole ring. The $\%$ conversions to the various $\beta-m \operatorname{Trp}$ derivatives varied from $40-96 \%$ and may be further improved by recycling the unreacted indole for further biotransformation. ${ }^{[12 a]}$ The preparation of enantiomerically pure L- $\beta$-mTrp derivatives in a single biotransformation offers significant advantages over the existing synthetic routes to these compounds. At least six different synthetic routes to $\beta$-mTrp derivatives have been reported (Figure S8), emphasising the importance of these compounds, and each synthesis requires between five and eight steps, including deleterious reagents, the use of expensive chiral auxiliaries, chiral catalysts or resolution steps with low overall yields.
Table 1. Kinetics of StTrpS $\left(\beta_{2}\right)$ enzymes with L-threonine and L-serine

\begin{tabular}{lccc}
\hline$\beta_{2}$ (substrate) & $\mathrm{K}_{\mathrm{m}}(\mathrm{mM})$ & $k_{\text {cat }}\left(\mathrm{min}^{-1}\right)$ & $k_{\text {cat }} / \mathrm{K}_{\mathrm{m}}\left(\mathrm{M}^{-1} \cdot \mathrm{min}^{-1}\right)$ \\
\hline WT (L-Thr) & $210( \pm 22)$ & $0.041( \pm 0.002)$ & $0.19( \pm 0.02)$ \\
L166A (L-Thr) & $340( \pm 36)$ & $0.21( \pm 0.01)$ & $0.61( \pm 0.07)$ \\
L166V (L-Thr) & $310( \pm 25)$ & $0.42( \pm 0.02)$ & $1.37( \pm 0.1)$ \\
WT (L-Ser) & $1.6( \pm 0.2)$ & $21 \pm 0.5)$ & $13000( \pm 6700)$ \\
L166A (L-Ser) & $52( \pm 6.6)$ & $11( \pm 0.8)$ & $220( \pm 180)$ \\
L166V (L-Ser) & $1.4( \pm 0.2)$ & $4.9( \pm 0.08)$ & $3600( \pm 600)$ \\
\hline
\end{tabular}

While 2-, 4-, 6- or 7-substituted indoles were accepted by StTrpS ( $\beta$ L166V), along with L-Thr, 5-subsituted indoles proved to be very poor substrates for the enzyme. To address this we choose to explore the possibility of using the flavin-dependent tryptophan-5-halogenase $\mathrm{PyrH}$ to derivatise $\mathrm{C} 5$ of the indole moiety of $\beta-m \operatorname{Trp} 1$. In addition to regioselectively halogenating L-Trp, ${ }^{[16]} \mathrm{PyrH}$ has been shown to be promiscuous and can halogenate a number of other aromatic compounds. ${ }^{[17]}$ The tryptophan halogenases are relatively unstable and inefficient biocatalysts. However, recent studies have shown that productivity of a tryptophan-7-halogenase (RebH) can be considerably improved through the generation of cross-linked enzyme aggregates (CLEAs). ${ }^{[18]}$ Accordingly a CLEA was prepared containing $\mathrm{PyrH}$, the flavin reductase Fre (for recycling the $\mathrm{FADH}_{2}$ cofactor), and alcohol dehydrogenase (for NADH regeneration). Using this CLEA, the $\beta$-mTrp 1 from StTrpS could be converted to 5 -chloro- $\beta$-mTrp 10 in a $62 \%$ yield using only $\mathrm{MgCl}_{2}, \mathrm{O}_{2}$ (from air) and isopropanol as stoichiometric reagents (Scheme 3). This represents a $40 \%$ overall yield of the two enzymatic reactions from the indole starting material. Substitution of $\mathrm{MgCl}_{2}$ with $\mathrm{NaBr}$, as inorganic halide donor allowed the similar preparation of 5-bromo- $\beta$-mTrp 11 in $41 \%$ yield. Recently our laboratory and the Sewald group both showed how halogenase enzymes can be integrated with palladium-catalyzed cross-coupling chemistry, in one-pot reactions, to affect the regioselective arylation or alkenylation of $\mathrm{C}-\mathrm{H}$ positions of aromatic scaffolds. ${ }^{[19]}$ Following this approach, we were able to affect the direct C5-arylation of $\beta$-mTrp 1 to give 5 -phenyl- $\beta$-mTrp 12, in a one-pot reaction with $63 \%$ yield, using the PyrH-CLEA to generate intermediate aryl bromide (11) and sSPhoS and $\mathrm{Na}_{2} \mathrm{PdCl}_{4}$ to catalyse cross-coupling with phenyl boronic acid. These results, coupled with our previous studies, ${ }^{[19 a]}$ indicate that combination of StTrpS ( $\beta$ L166V), with halogenases and transition metal catalysis can open the way to more highly modified $\beta$-mTrp derivatives that would be difficult to prepare directly from a functionalised indole precursor using TrpS.

While the exquisite stereoselectivity of TrpS is a major advantage, access to other distereoisomers would be desirable. For example the D-configured epimer of $1,(2 R, 3 S)-\beta-m \operatorname{Trp} 13$, is present in peptidomimetic drug candidates for diabetes, such as $\mathrm{L}-779,976$ (Scheme $1 \mathrm{~A}$ ). ${ }^{[1 \mathrm{c}, \mathrm{d}]}$ Given that we showed $(2 \mathrm{~S}, 3 \mathrm{~S}$ )$\beta$-mTrp 1 is a substrate for LAAO we envisaged affecting stereoinversion at the $\alpha$-position to give $(2 R, 3 S)-\beta-m \operatorname{Trp} 12$, via the non-selective reduction of the imine intermediate formed from the LAAO oxidation of 1 . Such cyclic oxidation-reduction procedures have been used successfully in the deracemization or epimerisation of other $\alpha$-amino acid substrates. ${ }^{[20]}$ Accordingly 1 was incubated with LAAO in the presence of an excess of ammonia-borane, using the established conditions, ${ }^{[20]}$ resulting in the formation of the $(2 R, 3 S)$-epimer 13 in $93 \%$ yield. The ${ }^{1} \mathrm{H}$ NMR of 13 clearly indicates the expected change in chemical 
shifts and coupling constant between the $\alpha$ and $\beta$ protons (Figure S6). The NMR and other analytical data are also in agreement with the literature. ${ }^{\text {[7a] }}$ Furthermore incubation of $\mathbf{1 3}$ with DAAO led to complete oxidation, whilst no reaction was observed with LAAO (Figure S7). The overall yield for the two step enzymatic preparation of $(2 R, 3 S)-\beta$-mTrp 13 from indole is ca. $66 \%$.

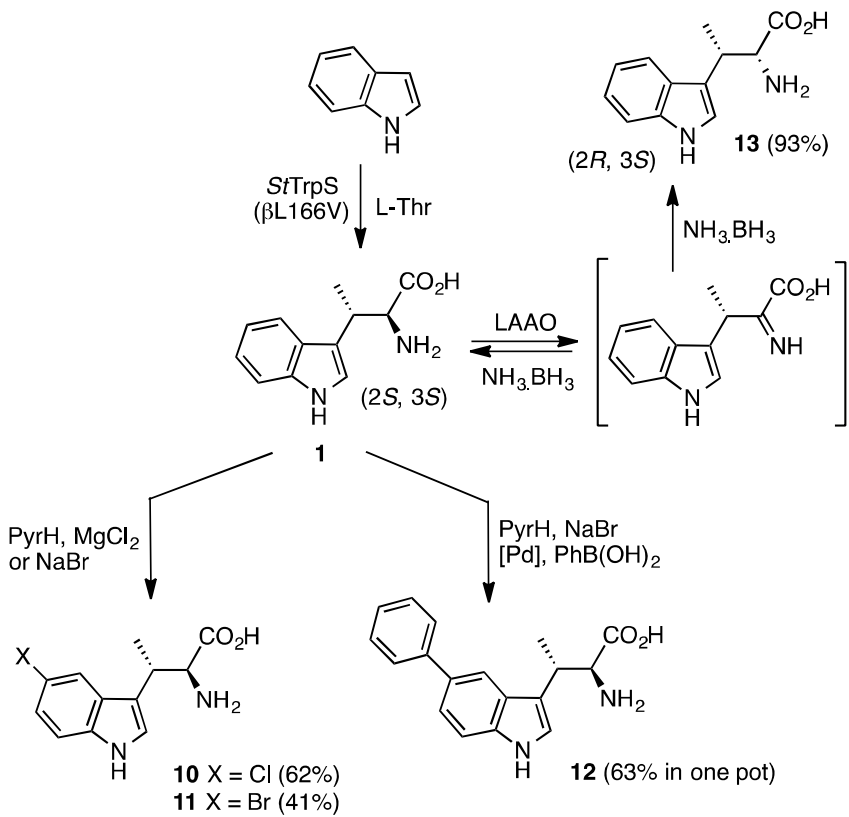

Scheme 3. Diversification of $\beta-m$ Trp 1 using: Halogenase $(\mathrm{PyrH})$ catalysed C5-chlorination \& bromination; C5-arylation using an integrated one-po halogenase-Suzuki-Miyaura cross-coupling procedure; ${ }^{[17]}$ and biocatalytic stereoinversion (\% isolated yields).

In order to generate $\beta$-mTrp with opposite configuration at C3, we envisaged utilising L-allo-threonine (2S,3S-Thr) as a substrate for TrpS. Based on the structure and mechanism of StTrpS (Figure 1), L-allo-Thr would, if accepted, be predicted to generate the $(Z)$ - rather than $(E)$-2-amino-2-butenoate intermediate (iv), leading to $(2 S, 3 R)-\beta$-mTrp. However, we found that L-allo-Thr is not a substrate for StTrpS or the mutants we prepared. Given that the L-allo-threonine aldolase (LATA) can be used to produce L-allo-threonine from glycine and acetaldehyde, ${ }^{[21]}$ engineering of TrpS to accept L-allo-threonine as an alternative amino acid substrate is an attractive future goal.

In summary we have demonstrated that tryptophan synthase (StTrpS) can utilise threonine, along with indole, in the preparation of enantiopure (2S,3S)- $\beta$-mTrp. Rational mutagenesis of StTrpS $\beta$-subunit changing Leu166 to Val, which is likely to better accommodate larger L-Thr substrate, provided an enzyme with ten-fold improved activity. The improved variant $(\beta L 166 \mathrm{~V})$ also accepts a range of substituted indoles and can be used to prepare 2-, 4-, 6- and 7-functionalised (2S,3S)- $\beta$-mTrp. Although 5-substitued indoles proved to be poor substrates for StTrpS ( $\beta L 166 V)$, the halogenase PyrH can be used to generate 5-chloro or 5-bromo-(2S,3S)- $\beta$-mTrp, with the more reactive bromo derivative enabling further derivitisation using cross coupling chemistry using a one-pot integrated approach. ${ }^{[19]}$ Finally, the use of LAAO in the presence of a non-selective reductant enables the complete stereoinversion of the $(2 S, 3 S)$ $\beta$-mTrp to the $(2 R, 3 S)$-diastereomer in near quantitative yields. StTrpS ( $\beta L 166 V)$ alone or in combination with halogenase or LAAO enzymes provides a convenient biocatalytic route, offering significant advantages over the synthetic procedures, to a range of functionalised $\beta$-mTrp derivatives, which have proven useful building blocks for drug synthesis. ${ }^{[1-4]}$ During revision of this manuscript, we became aware of a recent publication describing an evolved mutant of the tryptophan synthase $\beta$-subunit, from the thermophile Pyrococcus furiosus (PfTrpB), that can also be used to produce $\beta$-mTrp. ${ }^{[20]}$ Kinetic parameters were not determined in this alternative study, which precludes a direct quantitative comparison between the PfTrpB and StTrpS variants. However, unlike the PfTrpB variant which requires high temperature $\left(75^{\circ} \mathrm{C}\right)$ for optimal catalytic activity, the StTrpS mutant described here efficiently catalyse condensation of indoles with L-Thr at ambient temperature which is preferred for biocatalytic processes.

Acknowledgements: We thank BBSRC for a PhD studentship award to DF (allied to project BB/K002341/1 co-funded by Syngenta) and the University of Manchester for a PhD Scholarship award to $\mathrm{JL}$.

Keywords: Biocatalysis - Tryptophan synthase $\cdot$ Enzyme cascades $\bullet \beta$-Methyl- $\alpha$-amino acids $•$ Peptidomimetics

[1] a) C. Haskell-Luevano, L. W. Boteju, H. Miwa, C. Dickinson, I. Gantz, T. Yamada, M. E. Hadley, V. J. Hruby, J. Med. Chem. 1995, 38, 47204729; b) Z. Huang, Y. B. He, K. Raynor, M. Tallent, T. Reisine, M Goodman, J. Am. Chem. Soc. 1992, 114, 9390-9401; c) S. P. Rohrer, E. T. Birzin, R. T. Mosley, S. C. Berk, S. M. Hutchins, D. M. Shen, Y. Xiong, E. C. Hayes, R. M. Parmar, F. Foor, S. W. Mitra, S. J. Degrado M. Shu, J. M. Klopp, S. J. Cai, A. Blake, W. W. Chan, A. Pasternak, L. Yang, A. A. Patchett, R. G. Smith, K. T. Chapman, J. M. Schaeffer, Science 1998, 282, 737-740; d) L. Yang, S. C. Berk, S. P. Rohrer, R. T. Mosley, L. Guo, D. J. Underwood, B. H. Arison, E. T. Birzin, E. C. Hayes, S. W. Mitra, R. M. Parmar, K. Cheng, T. J. Wu, B. S. Butler, F Foor, A. Pasternak, Y. Pan, M. Silva, R. M. Freidinger, R. G. Smith, K Chapman, J. M. Schaeffer, A. A. Patchett, Proc. Natl. Acad. Sci. USA 1998, 95, 10836-10841.

[2] a) V. W. Cornish, M. I. Kaplan, D. L. Veenstra, P. A. Kollman, P. G. Schultz, Biochemistry 1994, 33, 12022-12031; b) V. J. Hruby, J. Med Chem. 2003, 46, 4215-4231; c) C. Haskell-Luevano, K. Toth, L. Boteju, C. Job, A. M. d. L. Castrucci, M. E. Hadley, V. J. Hruby, J. Med. Chem 1997, 40, 2740-2749.

[3] D. Tourwé, E. Mannekens, T. N. T. Diem, P. Verheyden, H. Jaspers, G. Tóth, A. Péter, I. Kertész, G. Török, N. N. Chung, P. W. Schiller, J. Med Chem. 1998, 41, 5167-5176; b) L. W. Boteju, G. V. Nikiforovich, C. Haskell-Luevano, S. N. Fang, T. Zalewska, D. Stropova, H. I. Yamamura, V. J. Hruby, J. Med. Chem. 1996, 39, 4120-4124; c) B. Y. Azizeh, M. D. Shenderovich, D. Trivedi, G. Li, N. S. Sturm, V. J. Hruby, J. Med. Chem. 1996, 39, 2449-2455; d) A. Lukaszuk, H. Demaegdt, I. Van den Eynde, P. Vanderheyden, G. Vauquelin, D. Tourwé, J. Pept. Sci. 2011, 17, 545-553.

[4] a) J. C. Sheehan, D. Mania, S. Nakamura, J. A. Stock, K. Maeda, J. Am Chem. Soc. 1968, 90, 462-470; b) T. W. Doyle, D. M. Balitz, R. E. Grulich, D. E. Nettleton, S. J. Gould, C.-h. Tann, A. E. Moews, Tetrahedron Lett. 1981, 22, 4595-4598; c) W. Balk-Bindseil, E. Helmke H. Weyland, H. Laatsch, Liebigs Annalen 1995, 1995, 1291-1294; d) Z. Hojati, C. Milne, B. Harvey, L. Gordon, M. Borg, F. Flett, B. Wilkinson, P. J. Sidebottom, B. A. M. Rudd, M. A. Hayes, C. P. Smith, J. Micklefield, Chem. Biol. 2002, 9, 1175-1187; e) H. He, R. T. Williamson, B. Shen, E. I. Graziani, H. Y. Yang, S. M. Sakya, P. J. Petersen, G. T. Carter, J. Am. Chem. Soc. 2002, 124, 9729-9736; f) H. He, R. T. Williamson, B. Shen, E. I. Graziani, H. Y. Yang, S. M. Sakya, P. J. Petersen, G. T. Carter, J Am. Chem. Soc. 2002, 124, 9729-9736; g) E. Rössner, A. Zeeck, W. A König, Angew. Chem., Int. Ed. 1990, 29, 64-65; h) Y. Hou, M. D. B. Tianero, J. C. Kwan, T. P. Wyche, C. R. Michel, G. A. Ellis, E. VazquezRivera, D. R. Braun, W. E. Rose, E. W. Schmidt, T. S. Bugni, Org. Lett. 2012, 14, 5050-5053; i) M. F. Freeman, C. Gurgui, M. J. Helf, B. I. Morinaka, A. R. Uria, N. J. Oldham, H.-G. Sahl, S. Matsunaga, J. Piel, 
Science 2012, 338, 387-390; j) Y-L. Du, L. M. Alkhalaf, K. S. Ryan Proc. Natl. Acad. Sci. USA 2015, 112, 2717-2722.

[5] a) A. Armstrong, S. P. Geldart, C. R. Jenner, J. N. Scutt, J. Org. Chem. 2007, 72, 8091-8094; b) S. Lou, G. M. McKenna, S. A. Tymonko, A Ramirez, T. Benkovics, D. A. Conlon, F. González-Bobes, Org. Lett. 2015, 17, 5000-5003; c) K. Sakaguchi, M. Yamamoto, T. Kawamoto, T. Yamada, T. Shinada, K. Shimamoto, Y. Ohfune, Tetrahedron Lett 2004 45, 5869-5872; d) R. Dharanipragada, K. VanHulle, A. Bannister, S. Bear, L. Kennedy, V. J. Hruby, Tetrahedron 1992, 48, 4733-4748; e) T. Ooi, D. Kato, K. Inamura, K. Ohmatsu, K. Maruoka, Org. Lett. 2007, 9 3945-3948; f) M. Alías, M. a. P. López, C. Cativiela, Tetrahedron 2004 $60,885-891$.

[6] a) C. Milne, A. Powell, J. Jim, M. Al Nakeeb, C. P. Smith, J. Micklefield, J. Am. Chem. Soc. 2006, 128, 11250-11259; b) C. Mahlert, F. Kopp, J. Thirlway, J. Micklefield, M. A. Marahiel, J. Am. Chem. Soc. 2007, 129 12011-12018.

[7] a) Y. Zou, Q. Fang, H. Yin, Z. Liang, D. Kong, L. Bai, Z. Deng, S. Lin, Angew. Chem., Int. Ed. 2013, 52, 12951-12955; b) S. D. Braun, J. Hofmann, A. Wensing, M. S. Ullrich, H. Weingart, B. Volksch, D. Spiteller, Appl. Environ. Microbiol. 2010, 76, 2500-2508; c) Y-T. Huang S.-Y. Lyu, P.-H. Chuang, N.-S. Hsu, Y.-S. Li, H.-C. Chan, C.-J. Huang Y.-C. Liu, C.-J. Wu, W.-B. Yang, T.-L. Li ChemBioChem 2009, 10 2480-2487

[8] a) M. R. Bauerle, E. L. Schwalm, S. J. Booker, J. Biol. Chem. 2015, 290, 3995-4002; b) S. Pierre, A. Guillot, A. Benjdia, C. Sandström, P Langella, O. Berteau, Nat. Chem. Biol. 2012, 8, 957-959; c) H. J. Kim, R. M. McCarty, Y. Ogasawara, Y.-n. Liu, S. O. Mansoorabadi, J. LeVieux, H.-w. Liu, J. Am. Chem. Soc. 2013, 135, 8093-8096.

[9] K. Kim, P. A. Cole, Bioorg. Med. Chem. Lett. 1999, 9, 1205-1208.

[10] M. F. Dunn, D. Niks, H. Ngo, T. R. M. Barends, I. Schlichting, Trends Biochem. Sci. 2008, 33, 254-264.

[11] C. K. Savile, J. M. Janey, E. C. Mundorff, J. C. Moore, S. Tam, W. R. Jarvis, J. C. Colbeck, A. Krebber, F. J. Fleitz, J. Brands, P. N. Devine G. W. Huisman, G. J. Hughes, Science 2010, 329, 305-309.

[12] a) R. J. M. Goss, P. L. A. Newill, Chem. Comm. 2006, 4924-4925; b) R. S. Phillips, Tetrahedron Asymmetry 2004, 15, 2787-2792.

[13] D. Niks, E. Hilario, A. Dierkers, H. Ngo, D. Borchardt, T. J. Neubauer, L. Fan, L. J. Mueller, M. F. Dunn, Biochemistry 2013, 52, 6396-6411.

[14] a) E. J. Faeder, G. G. Hammes, Biochemistry 1971, 10, 1041-1045; b) A. N. Lane, K. Kirschner, Eur. J. Biochem. 1983, 129, 571-582.

[15] M. D. Tsai, E. Schleicher, R. Potts, G. E. Skye, H. G. Floss, J. Biol. Chem. 1978, 253, 5344-5349.

[16] S. Zehner, A. Kotzsch, B. Bister, R. D. Süssmuth, C. Méndez, J. A Salas, K.-H. van Pée, Chem. Biol. 2005, 12, 445-452

[17] S. A. Shepherd, C. Karthikeyan, J. Latham, A.-W. Struck, M. L. Thompson, B. R. K. Menon, M. Q. Styles, C. Levy, D. Leys, J. Micklefield, Chem. Sci. 2015, 6, 3454-3460.

[18] M. Frese, N. Sewald, Angew. Chem., Int. Ed. 2015, 54, 298-301

[19] a) J. Latham, J.-M. Henry, H. H. Sharif, B. R. K. Menon, S. A. Shepherd, M. F. Greaney, J. Micklefield, Nat. Commun. 2016, 7, 11873; b) M. Frese, C. Schnepel, H. Minges, H. Voß, R. Feiner, N. Sewald ChemCatChem 2016, 8, 1799-1803.

[20] G. J. Roff, R. C. Lloyd, N. J. Turner, J. Am. Chem. Soc. 2004, 126, 4098-4099.

[21] a) J. Q. Liu, T. Dairi, M. Kataoka, S. Shimizu, H. Yamada, J. Bacteriol. 1997, 179, 3555-3560; b) N. Duckers, K. Baer, S. Simon, H. Groger, W. Hummel, Appl. Microbiol. Biotechnol. 2010, 88, 409-424.

[22] M. Herger, P. van Roye, D. K. Romney, S. Brinkmann-Chen, A.R. Buller, F. H. Arnold, J. Am. Chem. Soc. 2016, 138, 8388-8391. 
Entry for the Table of Contents (Please choose one layout)

\section{COMMUNICATION}

A mutant tryptophan synthase (StTrpS) catalyses the condensation of 2-, 4-, 6- \& 7-substituted indoles with threonine to give $(2 S, 3 S)-\beta$ methyltryptophans ( $\beta$-mTrp), which are important building blocks in drug synthesis. Addition of L-amino acid oxidase (LAAO) gives $(2 R, 3 S)-\beta$ mTrp. Halogenase (Hal) enzymes also provide halogenated $\beta$-mTrp derivatives that can be arylated in a one-pot chemobiotransformation.

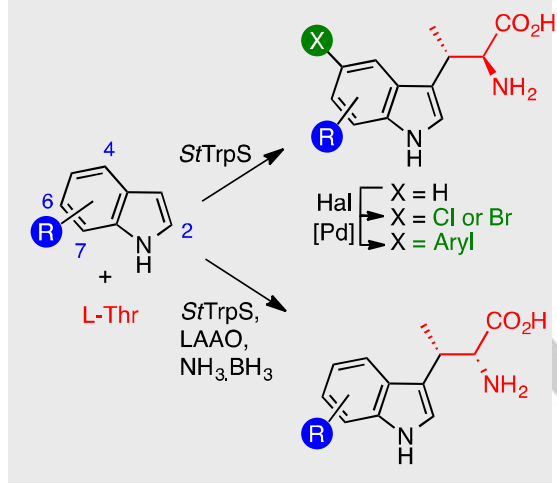

Daniel Francis, Michael Winn, Jonathan Latham, Michael F. Greaney and Jason Micklefield*

Page No. - Page No.

An Engineered Tryptophan Synthase Opens New Enzymatic Pathways to $\beta$-Methyltryptophan and Derivatives 